Books, videos, CD-ROMs, DVDs and any other relevant items submitted for a review in the $B D J$ should be addressed to: Kate Maynard, Assistant Editor, British Dental Journal, NPG, 4-6 Crinan Street, London N1 9XW

\section{Orthodontic-surgical treatment of dentofacial anomalies}

\author{
P. Ronchi \\ UK: Quintessence \\ price $€ 158$, pp 304 \\ ISBN 8874921012
}

This book is aimed at orthodontists and surgeons who are already involved in the combined treatment of facial deformity, or who are intending to become so. The principal author and all but one of the co-authors are listed as oral and maxillofacial surgeons. It is a translation from an existing Italian text, although the date of the original publication is not given.

It is divided into 14 chapters; all conclude with a bibliography except the last, which shows a varied selection of treated cases. The text is generally easy to follow, and well illustrated with photographs and diagrams. The subject matter is covered in a reasonably comprehensive and logical fashion, progressing from case assessment through presurgical orthodontics, surgical procedures and planning and then to post-operative treatment and complications. Some of the terminology used differs slightly from that familiar to UK readers, but not to the extent of hindering comprehension. There is also an accompanying DVD illustrating a bimaxillary surgical procedure, although some judicious editing and elimination of the unnecessary background music would improve this.

Does it succeed in its aims? As an orthodontist, I think it would be of more value to colleagues in that discipline seeking to enhance their knowledge of surgery rather than vice versa, but it is not quite as comprehensive as other publications covering the same field (eg Proffit, White and Sarver). There is little discussion on the psychological aspects of deformity, and some operative procedures that the authors now regard as obsolete are mentioned only in passing.
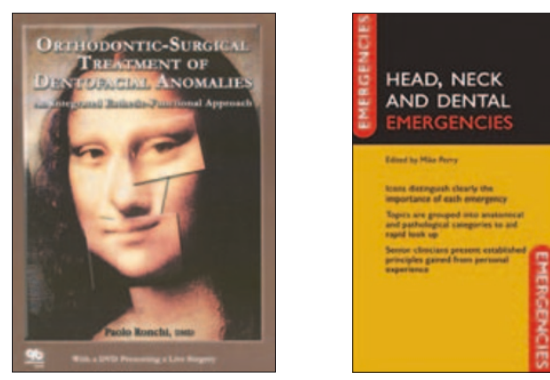

Furthermore, in Chapter 1, a general guide to the clinical examination of facial deformity would have been preferable to launching straight into descriptions of the specific characteristics of individual malocclusion traits. There are also some controversial views expressed (eg reeducation of tongue behaviour in open bite cases) with which many would disagree. Nevertheless, it is an enjoyable read, and contains much useful information and relevant clinical tips, such as a reminder to first consider the likely impact of planned sagittal changes when assessing transverse arch relationships. It should find a place in library collections, but is perhaps not sufficiently original to make it a worthwhile purchase for the individual reader who has ready access to the alternative.

J. W. Ferguson

\section{Head, neck and dental emergencies}

\section{Perry \\ UK: Oxford University Press \\ price $€ 19.95$, pp 462 \\ ISBN 0198529104}

This attractively presented little book is a further addition to the Oxford Handbook series. It is in the pocket reference format with a plastic flexicover to which we have become accustomed since the first $0 x$ ford Handbook of Clinical Medicine was published 20 years ago, with matching ribbon page markers in yellow and red.

It aims to provide the reader with a working approach to the diagnosis and management of patients presenting in the accident and emergency department, concentrating, as would be expected from the title, on urgent and emergency problems above the collar bones. However of necessity the first three chapters covering general assessment, first aid measures and infections take a rather more whole body approach as do the concluding glossary and last two sections on burns and miscellaneous conditions.

The bulk of the book runs sequentially through trauma and other emergency conditions involving the head, neck, face, ears, eyes, mouth, teeth and salivary glands. On average one topic within each overall heading is covered over three pages with a system of four icons used throughout to allow rapid identification of the degree of urgency. The explanatory key to the icons appears helpfully on both the inside front cover and again within the preface.

The layout comprising short notes, diagrams and photographs, together with a comprehensive index, provides the reader with an easily assimilated set of information which should prove extremely valuable in an emergency situation. There is an emphasis on maintaining a high index of suspicion and on frequent reassessment to ensure that pathology and potential complications are not missed. A minor disappointment was the quality of some of the photographs, the majority of which are in monochrome which contrast with those in colour printed on higher quality paper in the chapter devoted to the eye.

The editor, a maxillofacial surgeon who has extensive experience as a trauma team leader and now based in Belfast, has drawn together 14 contributors from a range of surgical specialties, ophthalmology and dentistry. The book is recommended mainly for junior doctors and also nurses in accident and emergency, oral and maxillofacial surgery, ENT, ophthalmology, anaesthetics and plastic surgery as well as for medical and dental undergraduates. However it is likely to have wider appeal even to more senior colleagues who may not regularly deal with emergencies around the head and neck but who occasionally may be called upon to do so.

J. Lowry 